\title{
Measures and suggestions for the prevention and control of the novel coronavirus in dental institutions
}

\author{
Wenjie Zhang, Xinquan Jiang \\ Department of Prosthodontics, Shanghai Ninth People's Hospital, College of Stomatology, Shanghai Jiao Tong University School of Medicine, \\ Shanghai Engineering Research Center of Advanced Dental Technology and Materials Oral Bioengineering and Regenerative Medicine Lab, \\ Shanghai Key Laboratory of Stomatology and Shanghai Research Institute of Stomatology, National Clinical Research Center of Stomatology, \\ Shanghai 200011, China \\ Correspondence to: Xinquan Jiang. 639 Zhizaoju Road, Shanghai 200011, China. Email: xinquanj@aliyun.com.
}

Received: 01 February 2020; Accepted: 19 February 2020; Published: 24 February 2020.

doi: 10.21037/fomm.2020.02.01

View this article at: http://dx.doi.org/10.21037/fomm.2020.02.01

Since the first cases of pneumonia of an unknown origin were identified in Wuhan, the capital city of Hubei province, China in December 2019, Chinese scientists have urgently and persistently worked to determine the causative agent. This novel coronavirus was officially termed as 2019$\mathrm{nCoV}$ or SARS-CoV-2 (1-3). Although the pathogen was quickly identified, the characteristics of its transmission were not initially estimated accurately. The highly contagious nature of SARS-CoV-2 further exacerbates the situation, as does the population's general susceptibility to it. The result of this is frequent human-human transmission among close contacts, including medical workers.

By the end of January 2020, coronavirus disease 2019 (COVID-19) outbreak had escalated into a serious public health emergency in China, leading to the level I emergency response, the highest level, across the entire country $(4,5)$. In the face of this rapidly spreading disease, the Chinese government has exerted itself to introduce a series of swift and effective targeted measures. Underpinning all of these actions are early detection, early isolation, and early treatment (6).

By February 14, 2020, the number of confirmed COVID-19 cases in China had exceeded 60,000, of which 1,716 cases (including 6 deaths) were medical workers. Although the number of new COVID-19 cases is reducing day by day, the total number of confirmed cases remains high, and the situation remains serious.

The rapid spread of COVID-19 is closely related to the manner in which SARS-CoV-2 is transmitted. However, the transmission modes of the virus have not been completely defined. At present, the respiratory droplet transmission mode and the contact transmission mode have been confirmed $(7,8)$. Whether the virus spreads through the fecal-oral route, aerosol or other methods is uncertain, and this poses greater challenges to the Chinese government in its efforts to prevent transmission. COVID-19's infectiousness during the incubation period further complicates its prevention and control. According to the latest reports, the longest incubation period so far is 24 days (9). In addition, the virus was detected in a sample from a Canadian patient who had been discharged from the hospital 14 days previously (10), although it is not clear whether the virus was still infectious.

In the process of preventing and controlling the disease, hospitals, as places where large numbers of people are brought close together, are especially important. Dental departments, in particular, face a higher risk of disease transmission by the very nature of dental treatment operations. The relevant characteristics of these operations are listed as follows: (I) the water mist generated by the airdriven high-speed handpiece, air polisher, and various other instruments mixes with the saliva and blood of patients, forming aerosols and diffusing into the surrounding air; (II) dental treatment is characterized by relatively long operation times, which results in the persistent existence of aerosols within a large area of the clinical office and introduces a potential risk of spreading disease; (III) conventional protective measures are not $100 \%$ effective, and patients have no protection during the treatment process; (IV) the incubation period and possibility of patients concealing medical history could easily lead to the spread of disease; and (V) saliva, blood, and mixed water droplets carrying the virus 
would contaminate dental treatment equipment. Through direct contact in the dentist's operation, both dental workers and patients are likely to become infectors and transmitters of COVID-19 $(11,12)$.

Based on the reasons above, many Chinese dentists and stomatological organizations have promptly reacted by ringing the alarm and calling for more attention to the disease via online platforms. Chinese Stomatological Association issued $A$ Letter to Patients Suffering Oral Diseases During Prevention and Control of Covid-19, which suggested that patients should be cautious when visiting the dentist, and also informed dental workers to protect themselves comprehensively. Along with the further developments of the epidemic situation, a nationwide restriction on dental clinics in controlling the number of patients and diagnostic and treatment procedures has been imposed. In parallel, the emergency channels for patients with oral and maxillofacial trauma, maxillofacial infection, severe swelling, severe tooth pain, and other emergencies have been maintained, while the treatment needs of patients with oral malignant tumors are still being addressed.

According to the current working guidelines for the prevention and control of COVID-19 in Chinese medical institutions, and the current working status of several domestic dental institutions, summarized here are the prevention and control measures and points of attention taken by Chinese dental institutions during different treatment sessions, for the reference of dental institutions and dental workers during the COVID-19 outbreak and those of other similar infectious diseases.

\section{Publicity and service work for society}

(I) Appeal to non-emergency patients to postpone their treatment plans to avoid cross-infection caused by clustering in hospitals. Inform emergency patients to wear masks for protection and minimize the number of accompanying persons as much as possible.

(II) Open a free online consultation platform for patients' convenience.

(III) Enhance oral health education and publicize health education through the Internet.

\section{Management and training for medical institutions}

(I) Take appointments or registration online or by telephone in all out-patient clinics to reduce gatherings of people; and arrange patients' visits according to different strict time periods to shorten their waiting time for treatment.

(II) Strengthen the training of employees in infection control and prevention, mainly via online teaching, in combination with on-site guidance; and equip dental workers with sufficient protective equipment which strictly complies with the protection requirements.

(III) Develop a regular reporting system. Individuals with a travel history to the epidemic area and/or a history of close contact with person(s) who have been to the epidemic area shall implement a self-quarantine observation for 14 days.

(IV) The body temperature of all employees must be taken before entering the workplace, and it is forbidden to work with illness.

\section{Pre-viewing and triage}

(I) Pre-viewing and triage workers should enhance the grade- 1 medical protection by additionally wearing goggles and gowns (Figure 1).

(II) Prepare thermometers (forehead or ear thermometer) for temperature measurement, and ask patients regarding their epidemiological contact history, fever, and respiratory symptoms.

(III) If the following conditions are encountered during triage, advise patients to leave and instruct them to go to the general hospital, and clean and disinfect the reception room as soon as possible.

(i) Body temperature $\geq 37.3{ }^{\circ} \mathrm{C}$, with symptoms of a cough, runny nose, fatigue, etc.;

(ii) A history of travel or residence in Hubei province, or contact with somebody who has a fever or has been to Hubei province within the past 2 weeks;

(iii) The patient's living or working area has confirmed cluster cases of SARS-CoV-2 infection.

\section{The diagnosis and treatment process}

(I) During the epidemic, the transmission characteristics of the virus and the particularity of oral diagnosis and treatment should be taken into account; high standards of protection should be adopted for all patients to avoid potential transmission risks.

(II) For the treatment of patients with trauma or inflammation without aerosol generation, healthcare workers should use enhanced grade-2 protection (non- 
A
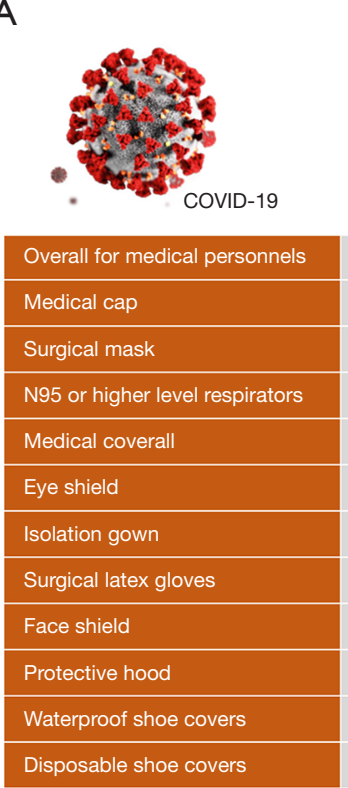
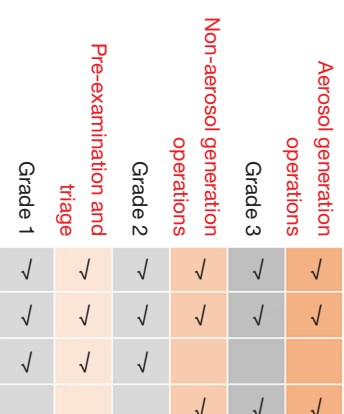
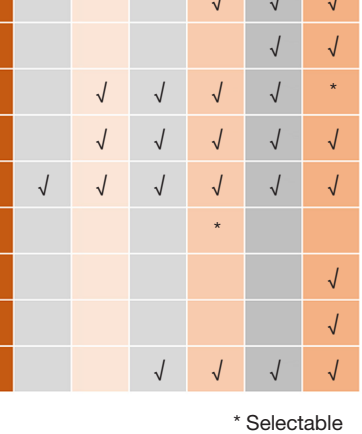

B

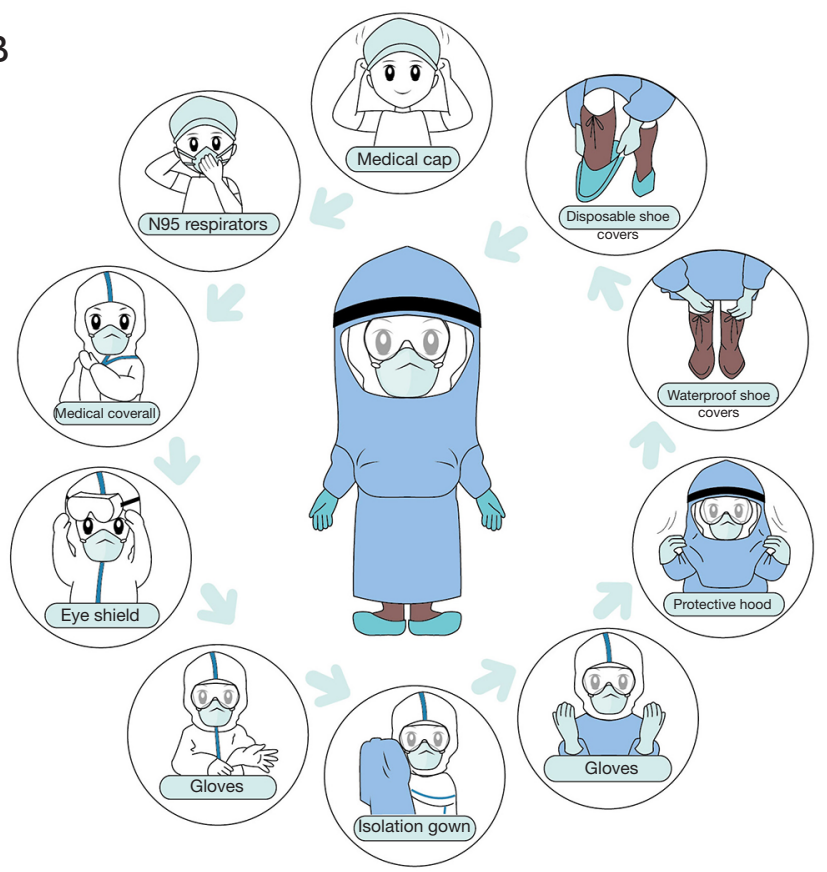

Figure 1 Recommended personal protective measures for dental workers, compared with the three-grade occupational protection strategies for medical personnel in China during the epidemic stage of novel coronavirus pneumonia.

aerosol generation operations in Figure 1). When using high speed turbo-charging handpieces and oral ultrasonic scalers that can generate aerosols and create an immersion environment, dental workers should use enhanced grade- 3 protection (aerosol generation operations in Figure 1).

(III) Give the patient a mouthwash $(0.5 \%$ hydrogen peroxide, povidone iodine $1 \%$, etc.) with virusinhibiting effect before the operation $(13,14)$; use a rubber dam for effective isolation; and use strong suction to reduce pollutant spread.

(IV) Change the mask every 4 hours and wash or sanitize the hands thoroughly.

(V) Remove the protective mask/goggles and protective clothing when leaving the clinic; perform personal hygiene treatment after work, and pay special attention to the protection of the respiratory tract and mucous membranes.

\section{Suggestions for the treatment environment}

(I) Carry out all treatments in a single treatment room. Control the number of patients who enter the waiting area.

(II) The oral diagnosis and treatment area, as well as the waiting area should be rigidly isolated. Good ventilation conditions are required, while mechanical ventilation should be adopted if necessary. Before the consultation, the room should be disinfected by ultraviolet irradiation and sprayed with a disinfectant containing 2,000 $\mathrm{mg} / \mathrm{L}$ of effective chlorine.

(III) Wipe and disinfect the object surfaces as well as the floor with a disinfectant containing 2,000 $\mathrm{mg} / \mathrm{L}$ of effective chlorine at least twice a day, and disinfect as soon as possible if there is contamination. Pay special attention to high-frequency contact surfaces (such as various handles, buttons, instrument panels, stair walkways, etc.).

(IV) Once the oral treatment is completed, each chair used by the patient should be wiped with $75 \%$ ethanol or 2,000 $\mathrm{mg} / \mathrm{L}$ disinfectant containing effective chlorine.

Undoubtedly, much remains unknown about COVID-19. Our measures for the prevention and control of the disease require more detailed optimization and improvements. The specific risk values of various clinical operations in dental practice need to be supported by more scientific data. Thus, related instruments and specifications should be developed and stipulated. To combat this sudden serious outbreak throughout the country, especially in Hubei province, a large number of dental practitioners have taken 
on the fight against COVID-19 directly. We highly salute these individuals, with the expectation that they can protect themselves properly. We sincerely hope that Chinese dental practitioners can undertake an important role in the prevention of the epidemic during its most critical period, treating patients suffering from oral diseases while preventing the spread of the disease. We believe that under the leadership of Chinese government, and with the full cooperation of the whole nation, the epidemic situation will be controlled as soon as possible. Victory remains with us.

\section{Acknowledgments}

The authors appreciate Xiaotian Lv for drawing the cartoon illustration.

Funding: None.

\section{Footnote}

Provenance and Peer Review: This article was a standard submission to the journal. The article has undergone external peer review.

Conflicts of Interest: Both authors have completed the ICMJE uniform disclosure form (available at https://fomm. amegroups.com/article/view/10.21037/fomm.2020.02.01/ coif). The authors have no conflicts of interest to declare.

Ethical Statement: The authors are accountable for all aspects of the work, and the questions related to the accuracy or integrity of any part of the work are appropriately investigated and resolved.

Open Access Statement: This is an Open Access article distributed in accordance with the Creative Commons Attribution-NonCommercial-NoDerivs 4.0 International License (CC BY-NC-ND 4.0), which permits the noncommercial replication and distribution of the article with the strict proviso that no changes or edits are made and the original work is properly cited (including links to both the formal publication through the relevant DOI and the license). See: https://creativecommons.org/licenses/by-nc-nd/4.0/.

\section{References}

1. Lu R, Zhao X, Li J, et al. Genomic characterisation and epidemiology of 2019 novel coronavirus: implications for virus origins and receptor binding. Lancet 2020;395:565-74.
2. Munster VJ, Koopmans M, van Doremalen N, et al. A Novel Coronavirus Emerging in China - Key Questions for Impact Assessment. N Engl J Med 2020;382:692-4.

3. Liu YC, Liao CH, Chang CF, et al. A Locally Transmitted Case of SARS-CoV-2 Infection in Taiwan. N Engl J Med 2020;382:1070-2.

4. Habibi R, Burci GL, de Campos TC, et al. Do not violate the International Health Regulations during the COVID-19 outbreak. Lancet 2020;395:664-6.

5. Heymann DL, Shindo N. COVID-19: what is next for public health? Lancet 2020;395:542-5.

6. Wang C, Horby PW, Hayden FG, et al. A novel coronavirus outbreak of global health concern. Lancet 2020;395:470-3.

7. Chan JFW, Yuan S, Kok KH, et al. A familial cluster of pneumonia associated with the 2019 novel coronavirus indicating person-to-person transmission: a study of a family cluster. Lancet 2020;395:514-23.

8. Li Q, Guan X, Wu P, et al. Early Transmission Dynamics in Wuhan, China, of Novel Coronavirus-Infected Pneumonia. N Engl J Med 2020;382:1199-207.

9. Guan WJ, Ni ZY, Hu Y, et al. Clinical characteristics of 2019 novel coronavirus infection in China. medRxiv 2020. doi: https://doi. org/10.1101/2020.02.06.20020974

10. Silverstein WK, Stroud L, Cleghorn GE, et al. First imported case of 2019 novel coronavirus in Canada, presenting as mild pneumonia. Lancet 2020;395:734.

11. Harrel SK, Molinari J. Aerosols and splatter in dentistry: a brief review of the literature and infection control implications. J Am Dent Assoc 2004;135:429-37.

12. Raghunath N, Meenakshi S, Sreeshyla H, et al. Aerosols in Dental Practice- A Neglected Infectious Vector. Br Microbiol Res J 2016;14:1-8.

13. Kampf G, Todt D, Pfaender S, et al. Persistence of coronaviruses on inanimate surfaces and its inactivation with biocidal agents. J Hosp Infect 2020;104:246-51.

14. Eggers M, Eickmann M, Zorn J. Rapid and Effective Virucidal Activity of Povidone-Iodine Products Against Middle East Respiratory Syndrome Coronavirus (MERS$\mathrm{CoV}$ ) and Modified Vaccinia Virus Ankara (MVA). Infect Dis Ther 2015;4:491-501.

doi: $10.21037 /$ fomm.2020.02.01

Cite this article as: Zhang W, Jiang X. Measures and suggestions for the prevention and control of the novel coronavirus in dental institutions. Front Oral Maxillofac Med 2020;2:4. 